\title{
The concept of the qualitology and grey system theory application in marketing information quality cognition and assessment
}

\author{
Majchrzak Joanna $^{1}$ (D) Goliński Marek ${ }^{1} \cdot$ Mantura Władysław $^{1}$
}

Published online: 17 July 2019

(c) The Author(s) 2019

\begin{abstract}
The article presents concept of the basics of qualitology and grey incidence clustering model application in the recognition and assessment of marketing information quality. In the first part of the paper, the concept of qualitative (qualitological) modelling of marketing information quality is explained. The issues of quality, marketing information quality and the evaluated marketing information quality are presented. Several steps are specified to recognize and asses the marketing information quality. In the presented concept, an innovative solution is an integration of the fundamental qualitative principles, operations and methods with the grey incidence clustering model. The developed concept facilitates the recognition of the marketing information quality in a systematic (holistic) manner, considering the state of features belonging to marketing information and their structure. The results presented constitute the basis for further research on quality management of the company's marketing information. The developed methodological solution was applied in a chosen industrial company. In the last part of the paper, directions for further research in the field of marketing information quality management in industrial companies are specified.
\end{abstract}

Keywords Pro-quality management · Marketing information quality · Grey clustering model · Qualitology

\section{Introduction}

The issue of marketing information quality management in industrial companies was selected for the conducted research. An industrial company is defined as an independent entity, running economically viable business operations, including a subsystem of

Majchrzak Joanna

joanna.majchrzak@put.poznan.pl

1 Marketing and Economic Engineering Department, Faculty of Engineering Management, Poznan University of Technology, 11 Strzelecka Str., 60-965 Poznan, Poland 
product manufacturing. The relations between industrial companies and market environment entities are usually long-term and have the form of cooperation or competing, in processes of solving complex problems, most often related to searching for new, innovative technical solutions, as well as organizational, personnel and other solutions (Grönroos 1994). Management of the company's relations in a complex and dynamically changing market requires the so-called new generation competences, enabling to create cross-functional organizational knowledge (Korhonen-Sande and Sande 2014; Spychała et al. 2017) and effective adaptation of the enterprise to the changing conditions of the market environment (Rajnoha 2014; Szafrański et al. 2019). The integration and globalization of the market result in the increased range and complexity of all relations of the company on the market. Industrial companies' organizational units communicate with different entities from the market environment, such as, e.g. suppliers, competitors, education entities, science systems, authorities, local community and political organizations. Companies' opportunities for market environment cognition and influencing are increased. This is accompanied by rapid growth in the amount of information processed by their employees. Without reasonably managed information activities, the threat of the so-called "information contamination" (Sienkiewicz 1983) appears, meaning the excess information as compared to the people cognitive capacities for information structuring. The company's communication processes management, the aim of which is information transfer, understanding and adaptation to the market environment, is one of the main functions of marketing. Marketing information is important in all phases related to the process of designing, manufacturing and using the company's products (Mantura 2015). In the area of research and product development, the so-called marketing information system ensuring a structured inflow of information for making marketing decisions is particularly important. In the area of production preparation and product manufacturing, marketing information enables control of manufacturing regarding timeliness, number and quality differentiation of the products according to the forecast demand. In the area of product sales, marketing information has an impact on the customers' interest, ensures the right time and place for selling and maintaining the adequate quality of products and customer service. In the area of exploitation and liquidation, marketing information leads to examining the product users' opinions, the level of meeting their requirements, contributing to product improvement and an increased level of satisfaction among the company's customers. In recent years, the need for integrated perspective on marketing information has been recognized. In the aspect of marketing cognitive activities this refers to management of marketing information which is created by various people form organizational units of the company (Lu et al. 2007). In the aspect of marketing creative activities, an integrated approach to marketing information contributes to the so-called synergy effect in shaping the desired changes in market environment. The developing theory and practice in this field mostly refers to the principles of marketing (basic marketing), considering marketing elements, marketing mix, ${ }^{1}$ and their relations (Schultz and

\footnotetext{
1 The notion of the so-called marketing mix and the idea of reflecting marketing as a set of elements was first introduced by Borden (1964), who defined 12 marketing components. The marketing mix model was developed in numerous studies and various marketing mix models were introduced (Goi 2009). In the literature and practice of marketing activities the references are most often made to the marketing mix
} 
Schultz 1998; Keller 2001, 2010; Andersen 2001; Holm 2006). The works in the field of marketing management related to, among others, the knowledge concerning design of the methods, techniques and tools for the company's marketing management are still limited (Lindgreen and Crawford 1999; Loots and Grobler 2014). This work integrates the principles of quality management with marketing to prepare a concept of cognition and assessment of the quality of marketing information created as a result of an industrial company's marketing communication processes with entities from the market environment. Growth in the amount of information as well as the development of information processes in daily life, particularly in the production area, is a great challenge for the man. Designing and performing manufacturing processes, regardless of the advances in automation, it should be remembered that the key factor deciding about success of any project is the human factor (Graczyk-Kucharska et al. 2018; Hermann et al. 2016). In the area of marketing activities, communication problems and employees' interpersonal competences are significant. Effective achievement of the company's goals cannot be detached from the human factor, which manifests itself in the entire information processes in the company and affects the set of features describing information quality. When implementing the effects of the study concerning research into the factors related to the quality of marketing information in practice, for effectiveness in attaining the goal, the environmental conditions affecting communication between the employees should also be analyzed (Salvendy 2012). The set of information features and their states will be subject to standardization, largely dependent on the standardized procedures of the whole management process, while the issue of the human factor will affect its variability, related to a significant level of uniqueness and diversity (Bruhn and Georgi 2006).

\section{Category of marketing information quality}

The category of quality was determined for the first time in the works of Plato's, who invented a new word "poiotes" "what-ness", as we might say, or "of-what-kindness". That word was later translated by Cicero into Latin "qualitas" from the word "qualis", being in its primary meaning used to refer to characteristics, properties, attributes of the given thing (Sower and Fair 2005). The sources of quality-based view on the reality, i.e. made through the quality categories, can be found in the basic branches of philosophy systems, such as (Mantura 2012):

- Ontology, referring to the way of existence and structure of reality,

- Epistemology, referring to objects' contents, boundaries, methods and realness of human cognition,

- Axiology, referring to values and objects, boundaries and evaluation criteria.

Footnote 1 (continued)

model proposed by McCarthy (1964), the so-called four Ps of marketing: product, price, promotion and place. 
The ontological concept assumes that the world consists of things having some special properties. Things can be complex, consist of other things. Properties are represented by features, which in processes of cognition and creation are assigned to things, with the reference to human needs, capacities and constraints. States of features belonging to things in the given period indicate the state of their quality in this period (Wand and Wang 1996). Aristotle, the author of the theory of matter and form, included quality in the set of ten most general categories of description and cognition of the substance state. The category of quality in his concept is a set of specific features distinguishing the given object from other objects of the same type (Aristotle 2012). The category of quality meets the general, significant and universal cognitive (epistemological) function with regard to each object. This function is formulated in the answer to the general question: what the object is, was or will be like? or how it exists, existed or will exist? (Mantura 2012). Plato in his philosophical system defined the material world as an imperfect reflection of the really and objectively existing perfect ideas, patterns (Sower and Fair 2005). In this perspective, the quality is related to specific things and is used to refer to the degree of perfection achieved by them (compared with the perfect ideas of things). Such an understanding of the category of quality facilitate the value-based, preferential objects ordering. In general practice and social awareness, quality is most often a specified type of value, determined by the requirements fulfillment by the given object. Thus, these are the evaluated (axiological) definition of quality (Mantura 2010), e.g.:

- "fitness for use" (Juran 1992),

- "conformance to requirements" (Crosby 1985),

- "translate future needs of the user into measurable characteristics" (Deming 1986),

- “best for certain customer condition" (Feigenbaum 1951),

- "meeting requirements" (ISO 9001),

- or, in the area of service quality assessment "meeting or exceeding customer expectations" (Parasuraman et al. 1988).

In the Polish literature, the concept of introducing an interdisciplinary domain of knowledge dealing with any issues regarding quality, called qualitology, as the science of quality (which is treated as the holistic view and organization of the existing knowledge of quality), is being developed. This concept appeared quite recently, introduced by the work published in 1973 by Romuald Kolman. The present works on qualitology create the foundations for the application of the quality category in solving not only axiological problems, related to the objects value, but also in resolving epistemological questions leading to cognition and designing of qualitative models of objects (Kolman 1973, 2009; Kolman et al. 2009; Mantura 2010; 2012; Borys 1980; Azgaldov et al. 2015). Research referring to the fundamentals of qualitology can be classified into two basic fields (Borys 2012), i.e. qualitonomy, as the descriptive field of the quality theory and qualimetry as the formal field in the quality theory dealing with the use of numeric (mathematical-statistical) methods in the quality theory and their application (i.a. Kosacka et al. 2015; Kijewska and Goliński 2017; Szafrański 2017; Więcek-Janka et al. 2017; Małecka 2018). In the 
conducted research, according to the basics of qualitology (Mantura 2010), the epistemological (descriptive) definition of quality of an object is used, together with the axiological criterion specifying the evaluated (hierarchical, relative) quality of the object which is being the subject of research. This approach makes the foundation for defining the quality of marketing information.

Definition 1 The marketing information quality is a set of features belonging to it.

$$
J^{I m}=\left\{c_{1}^{I m}, c_{2}^{I m}, \ldots, c_{n}^{I m}\right\} .
$$

Here $J^{I m}$ is marketing information quality, $\left\{c_{1}^{I m}, c_{2}^{I m}, \ldots, c_{n}^{I m}\right\}$ is the set of features belonging to marketing information.

Conceptualization of marketing information quality consists in recognition, postulating and formulating the set of features belonging to it. Information quality is treated in the holistic manner, which means it is expressed by the set of features belonging to it and their structure. In reality, the features are identified in the form of their specific, individual states. The state of marketing information quality is determined at least by one state of each feature belonging to it.

Definition 2 A state of marketing information quality is a set of states of features belonging to it.

$$
J_{s}^{I m}=\left\{s_{c 1}^{I m}, s_{c 2}^{I m}, \ldots, s_{c n}^{I m}\right\} .
$$

Here $J_{s}^{I m}$ is the state of marketing information quality, $\left\{s_{c 1}^{I m}, s_{c 2}^{I m}, \ldots, s_{c n}^{I m}\right\}$ is the set of the states of individual features, $c_{1}^{I m}, c_{2}^{I m}, \ldots, c_{n}^{I m}$, belonging to marketing information.

Analyzing the marketing information features and their states in the relation to the defined system of needs, goals and requirements of the man is the basis for transforming the state of marketing information quality into evaluated (relative) state of marketing information quality (cf. Mantura 2010).

Definition 3 The evaluated marketing information quality is value-based and value-structured set of features belonging to it.

Definition 4 The evaluated state of marketing information quality is value-based and value-structured set of states of features belonging to it.

A general and universal evaluation criterion of marketing information quality is assumed as the effectiveness of satisfying the set of needs, achieving the objectives and meeting the requirements related to the marketing functions in an industrial company.

The marketing system has diverse functions in the industrial company, such as, among others, marketing research, marketing communication, marketing based products designing, promotion of the company and its products, distribution, 
preparing economic conditions for exchange, planning company's market-oriented development, competition, supply, sales, trade negotiations, customer relations management, integration with other functions in the company, marketing budget management, and others (Mantura 2015). The selected objectives of marketing assigned to the marketing functions in the company have been presented in Table 1. The marketing communication function, which is a subject matter of this research, is related to the marketing information transmission and contributes to performance of all other marketing objectives and functions. Further in this work, designed activities are presented, leading to cognition and evaluation of the state of marketing information quality which is a result of an industrial company's marketing communication.

\section{Designing the concept of marketing information quality cognition}

The subject of the authors' research is the quality of marketing information shaped within marketing communication by transferring information between organizational units within the company and with organizational units of entities from the company's market environment. The issue of information quality is the subject of numerous research projects regarding such aspects as, among others, integration of different sources of information (Maurer and Mehmood 2015), using different sources of information in multi-attribute decision making (Jiao et al. 2016), capacity decisions under symmetric and asymmetric information (Kaya and Caner 2018), or efficiency in information acquisition ( $\mathrm{Li}$ et al. 2018), retrieving information under uncertainty and noise prone data (Weber et al. 2008), or ellipsoidal uncertainty of information in dynamics target-environment networks (Kropat et al. 2009). The methods of uncertainty research, such as grey systems, statistics, fuzzy math or rough set, have been widely applied for the research into information quality (i.a. Xie 2013; Liang et al. 2006; Słowiński et al. 2000; Maity et al. 2016, 2019; Roy et al. 2017a, b, c, 2018). In this study the infological concept of information is adopted, i.e. the concept developed by Swedish scholars, Sundgren and Langefors (Sundgren 1973; Langefors 1980), according to which information is the representation (description) of a specific part of the reality in the observer's mind. In the infological sense, information is subjective, dependent on the observer. ${ }^{2}$ In this perspective, information is the product of human thought operating in minds which reflect the reality and create the immaterial reality (Mantura 2012). Marketing information, formulated within marketing communication, meets two fundamental functions (Grönroos 1995; Holm 2006; Kitchen and Burgmann 2015). The first, cognitive one, allows creating, recording and storage of informative reflection of certain market elements. These elements, in the qualitative perspective are represented by economic, technical, demographic, cultural, legal, political, control, natural environment, and in the subjective perspective by various entities from the market environment such as suppliers, competitors, education entities, science systems, authorities,

\footnotetext{
${ }^{2}$ Information which is not dependent on the observer is objective information, namely information in the datalogic sense.
} 
Table 1 Selected marketing functions and objectives. Source: own study based on Mruk et al. (1996), Andersen (2001), Mirbagheri and Hejazinia (2010), Keller (2010), Kotler and Keller (2012), Wirtz et al. (2014), Mantura (2015), Majchrzak (2018)

\begin{tabular}{ll}
\hline Selected marketing function & Marketing objectives \\
\hline
\end{tabular}

Marketing research

Marketing communication

Promotion of the company and products-

Promotion of the company and its products

Preparing economic conditions for exchange

Distribution

Sales and trade negotiations

Customer relations management

Marketing budget management

Integration with other functions in the company
Identification of customer needs and demand, competitors' activities, level of product awareness; determination of the level of effectiveness of promotional activities and customer satisfaction

Transfer of information adequate to the company's internal and external goals; understanding market participants, their needs and behaviors; influencing the market environment, stimulation of market participants' behaviors

Preparation of recommendations for research and development department, participating in design and development activities, technology transfer; market-oriented and innovation-oriented designing of product characteristics; optimization of product quality and assortment structure

Developing strong brands, acquisition, maintenance or regaining lost customers, increasing the degree of customer loyalty, creating image and reputation of the company

Determination of product prices, discounts, bonuses, payment terms, credit conditions

Obtaining a certain level of market coverage, ensuring proper availability of products and convenience of purchase

Obtaining the determined level of sales and revenue, market share, negotiating favorable terms of sale

Increased level of customer satisfaction and loyalty, through e.g. improvement in the quality of products, customer service and assortment structure adapted to customer's needs; pursuit to maintain long-term and mutually favorable relations

Optimization of the structure of expenses; achieving a certain level of sales; rationalization of marketing activities cost; planning a competitive budget; growing income per share and growth in the company's market value

Creating the synergy effect and increased effectiveness of the company's activities; integration with the manufacturing system to learn the technological conditions of products manufacturing, and with the distribution system, to learn the potential to obtain new market segments, with the sales system, to improve the level of customer service

local community and political organizations. The second function of marketing information is the communication-stimulating function, allowing transfer of information and communication between entities on the market as well as affecting their 


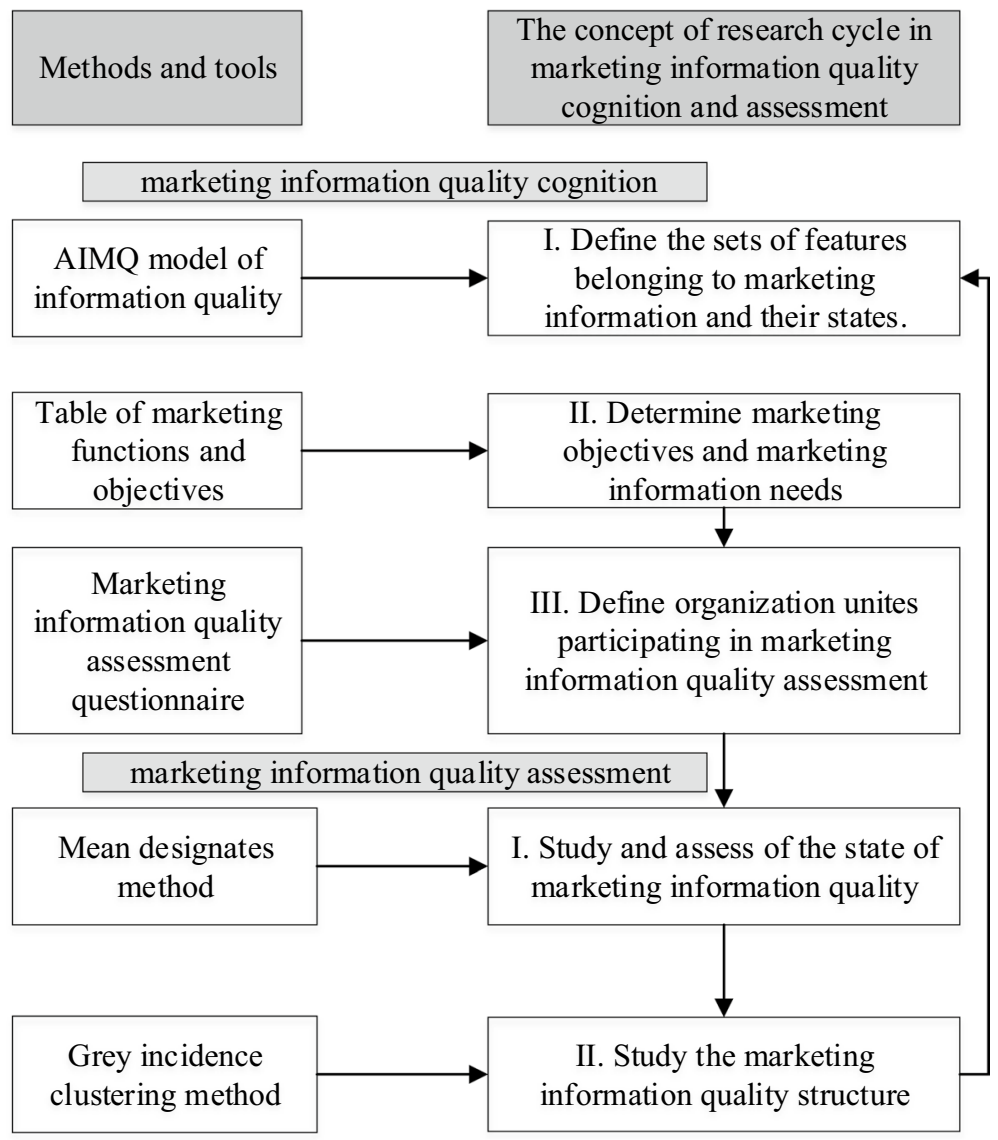

Fig. 1 The cycle of steps in cognition and assessment of marketing information quality. Source: own study

behaviors. In order to prepare a concept of cognition of the marketing information quality, the sets of features belonging to marketing information and their states are determined. Then, the method of measuring the states of these features, including preparation of a questionnaire to evaluate the state of marketing information quality is proposed. Finally, the appropriate calculation formulas to assess the state of marketing information quality are adopted and the directions for further marketing information quality improvement are proposed. In order to implement the above actions, reference was made to the foundations of the qualitology and the theory of grey systems, as well as selected methods for assessing the quality of information. The sequence of these activities is presented in Fig. 1, and the essence of their implementation and the legitimacy of the use of selected methods and tools are discussed below.

The first step in the cognition of marketing information quality is determination of the set of marketing information features. Studies and practice in the field 
of information quality most often adopt the axiological, evaluated set of information features using the usability of information as the criterion of its value, according to Juran's definition of quality which is "fitness for use" (Bizer and Cyganiak 2009). Knight and Burn (2005), examining information quality on the World Wide Web, based on the literature review, introduced various models of information quality. Analyzing the quality of marketing information, in this study the information quality model developed by Wang and his team on information quality research and used in the method of assessment and information quality improvement, AIMQ (Wang 1998; Lee et al. 2002) is adopted. Substantial amount of research in the field of information quality management, refer to this information quality model, as they refer to the issue of examining and assessing information quality (Michnik and Lo 2009; Chen and Tseng 2011), adopting its selected elements (Raghunathan 1999; Bizer and Cyganiak 2009; Shankaranarayanan and Cai 2006) or developing new models on its basis (Bovee et al. 2003). The information quality model and the AIMQ methodology were developed as a result of complex works based on the literature review and analysis of information quality models applied in practical operations of companies. As a result, a model of information quality, which is appropriate for information quality management has been developed. In the AIMQ method, information quality is defined by fifteen features belonging to information, such as (Lee et al. 2002): accessibility, amount, believability, completeness, consistent representation, concise representation, ease of operation, free of error, interpretability, objectivity, relevancy, reputation, security, timeliness, understandability. In this paper, designing concept of the marketing information quality cognition and assessment and its application in Polish industrial company, some of information features have been aggregated. These features are: understandability and interpretability, believability and reputation (due to similarity of their meaning in the translation into Polish), consistent representation, concise representation and accessibility (due to noticed dependence being that information is accessible if its form has consistent and concise representation), objectivity and completeness (due to the infological concept of information adopted in this paper and the occurring dependence such that the information about a given subject is complete if it takes into account different perspectives of its cognition). The adopted set of marketing information features and the questions leading to the evaluation of their states, which are based on information features and questions from AIMQ method (Lee et al. 2002) verified in terms of their accuracy and reliability, have been presented in Table 2. The adequacy of these features and listed questions for the recognition and evaluation of the marketing information quality has been verified in the authors' earlier research work, concerning the development of integrated marketing communication quality management method in the industrial company (Majchrzak 2018). Analyzing the states of features belonging to marketing information, the method of the quality relativization (Kolman 2009) was applied. In this method the prescribed scores are assigned to each of the distinguished states of features, such as: 5 (very favorable state), 4 (favorable state), 3 (average state), 2 (unfavorable state), 1 (very unfavorable state).

The second step in the cognition of marketing information quality is to indicate the current and important objectives of the company's marketing. This activity is carried out by the marketing management team with the support of the management 
Table 2 Set of marketing information features and questions leading to the evaluation of their states. Source: own study based on Lee et al. (2002), Majchrzak (2018)

\begin{tabular}{|c|c|}
\hline $\begin{array}{l}\text { Features belonging to mar- } \\
\text { keting information }\end{array}$ & $\begin{array}{l}\text { Question leading to evaluation of the state of features belonging to mar- } \\
\text { keting information }\end{array}$ \\
\hline$c_{1}^{I m}$-amount & $\begin{array}{l}\text { 1.1. Is the amount of information sufficient? } \\
\text { 1.2. Does the amount of information meet our needs? }\end{array}$ \\
\hline$c_{2}^{I m}$-understandability & $\begin{array}{l}\text { 2.1. Is the information understandable? } \\
2.2 \text {. Is the information easily interpretable? }\end{array}$ \\
\hline$c_{3}^{I m}$-relevancy & $\begin{array}{l}\text { 3.1. Is the information useful in our work? } \\
\text { 3.2. Is the information useful for solving problems? } \\
\text { 3.3. Is the information useful in planning future work? }\end{array}$ \\
\hline$c_{4}^{I m}$-completeness & $\begin{array}{l}\text { 4.1. Is the range of information appropriate? } \\
\text { 4.2. Is the information detailed enough? }\end{array}$ \\
\hline$c_{5}^{I m}$-free of error & $\begin{array}{l}\text { 5.1. Is the information correct? } \\
5.2 . \text { Is the information accurate? }\end{array}$ \\
\hline$c_{6}^{I m}$-security & $\begin{array}{l}\text { 6.1. Is the information protected against unauthorized access? } \\
6.2 . \text { Is the information protected against information noise? }\end{array}$ \\
\hline$c_{7}^{I m}$-timeliness & $\begin{array}{l}\text { 7.1. Is the information obtained in time? } \\
7.2 . \text { Is the time of obtaining information appropriate? }\end{array}$ \\
\hline$c_{8}^{I m}$-accessibility & $\begin{array}{l}\text { 8.1. Is the information easily accessible? } \\
\text { 8.2. Is the information reliable? } \\
\text { 8.3. Is the information consistent? }\end{array}$ \\
\hline$c_{9}^{I m}$-believability & $\begin{array}{l}\text { 9.1. Is the information trustworthy? } \\
\text { 9.2. Is the information meaningful? }\end{array}$ \\
\hline$c_{10}^{I m}$-ease of operation & $\begin{array}{l}\text { 10.1. Can the form of information transfer be controlled? } \\
\text { 10.2. Can the information be aggregated with other pieces of information? }\end{array}$ \\
\hline
\end{tabular}

of the industrial enterprise and the use of the set of basic marketing functions and objectives (see Table 1). The developed set of marketing functions and objectives can be expanded with additional marketing functions and goals specific to the operations of a given company. Next, the marketing management team distinguishes the marketing communication processes of the company, within which marketing information useful for the implementation of the indicated marketing objectives is shaped.

The third step in the cognition of marketing information quality is the development of a questionnaire containing a set of questions in accordance with the adopted marketing information quality model (see Table 2). The questionnaire is addressed to the organizational units of an industrial enterprise or organizational units of market environment entities acting as the sender and recipient in separate marketing communication processes. The value of the states of individual features belonging to marketing information is calculated by averaging respondents' scores. The results are presented in the form of the vector variable of the evaluated state of marketing information feature.

Formula 1 Observation vector of evaluated states of the feature belonging to marketing information: 


$$
s_{c i}^{I m}=\left[s_{c i}^{I m}\left(J o_{1}\right), \ldots, s_{c i}^{I m}\left(J o_{1}\right)\right] .
$$

Here $s_{c i}^{I m}$ is the state of $i$-feature belonging to marketing information, $s_{c i}^{I m}\left(J o_{1}\right)$ is the state of $i$-feature belonging to marketing information assessed by $k$-person of the organizational unit in the industrial company or in market environment entity, and $k=1,2, \ldots, n$.

The set of observation vectors of evaluated states of marketing information features is the basis for further research leading to the industrial company's marketing information quality assessment.

\section{Designing the concept of marketing information quality assessment}

The primal assumption for the design process of the marketing information quality assessment is to refer to the fundamentals of the systemic thinking. The reference to systemic approach consists in analyzing marketing information quality in a comprehensive, holistic perspective as a set of its features and their relations as well as relations with the environment, including relations with the supersystem such as the marketing system. The systemic approach to the quality of marketing information allows to apply methods, techniques and tools of various concepts and theories adopting the principles of the systemic thinking. Designing the concept of marketing information quality assessment the methods, techniques and tools of two different theories have been applied: qualitology (Kolman's averaging quality rating method is adopted to calculate the value of the indicator and class of marketing information quality), grey system theory (grey cluster method is adopted to study of the relations between the states of individual marketing information features). The legitimacy and the essence of reference to the basics of qualitology in the study of the quality of marketing information is explained at the stage of determining the category of marketing information quality. The legitimacy of the application of the rudiments of grey systems theory is justified by the fact that research methods and procedures developed within this theory entitle to inference based on incomplete, uncertain and few information about the systems being researched. This means that the information of system elements (or parameters), information on their structure, information on boundary and information on movement is incomplete. The theory of grey systems was created relatively recently in China, in 1982. It was created by Chinese scholar professor Deng Julong and presented in the work "The Control Problems of Grey Systems" which was published in the journal Systems and Control Letters. It is assumed where, like in control theory, that the darkness of colors is used to indicate the degree of clarity of information. The word "black" is used to represent unknown information, "white" for completely known information, and "grey" for that information which is partially known and partially unknown (Liu and Lin 2006).

Grey information, the representation of a particular part of reality, is described with grey numbers. A grey number stands for "an indeterminate number that 
takes its possible value within an interval or a general set of numbers" (Liu et al. 2017). A grey number is represented using the symbol " $\otimes$ ". There are several types of grey numbers, such as, among others, grey number with only lower or upper bound, interval grey number, continuous and discrete grey number (Liu et al., 2017). In the conducted research into the quality of marketing information, we are dealing with the interval grey number, i.e. the kind of grey number $\otimes$ which has both a lower bound $(\underline{a})$ and an upper bound $(\bar{a})$, written $\otimes \in[\underline{a}, \bar{a}]$. The lower bound $(\underline{a})$ is a score 1 which stands for the very unfavourable state of feature belonging to marketing information. The upper bound $(\bar{a})$ is a score of 5 which stands for the very favourable state of feature belonging to marketing information. Thus, the interval grey number $\otimes \in[\underline{a}, \bar{a}]$ is determined in the conducted research by $\otimes \in[1,5]$, wherein as opposed to the interval number, the interval grey number is only one value in interval $[1,5]$. The states of features belonging to marketing information are evaluated by the employees of a company's organizational units. Therefore, in the conducted research it is assumed that the grey number is represented by the white number obtained through experience of people who evaluated the state of features belonging to marketing information (see Formula 1). Thus, being aware of human cognitive limitation, the interval grey number referring to the state of individual marketing information features takes its whitenization value $\widetilde{\otimes}$ such as:

$$
\widetilde{\otimes}=s_{c i}^{I m}\left(J o_{k}\right)
$$

Here $s_{c i}^{I m}\left(J o_{k}\right)$ is the state of $i$-feature belonging to marketing information assessed by $k$-person of the organizational unit in the industrial company or in market environment entity, and $k-1,2, \ldots, n$.

In the theory of grey systems, whitenization value $\widetilde{\otimes}$ expresses the result of representation (transformation) of a grey number by a white number through experience or through a certain method (Liu et al. 2017). In this paper whitenization value $\widetilde{\otimes}$ is determined based on experience of the people of a company's organizational units. Another method of determining the whitenization value of an interval grey number using certain methods based on the positioned coefficient of the interval grey number was presented, inter alia, in determining the whitenization value of the capacity of supply and demand in the method of solving multi-objective two-stage grey transportation problem using utility function with goals (Roy et al. 2017a, b, c). Moreover, also the information referring to the set of features assigned to marketing information is incomplete. Considering the above, in this work the grey system theory clustering method (Liu et al. 2017) is applied to deal with the uncertain system of marketing information quality. Incomplete information is a common phenomenon in social systems, such as considering in this research marketing system within an industrial company. The selected research methods of qualitology and grey system theory are based on mathematical formulas, thus their applications are understandable and unambiguous. The first step in assessing the quality of marketing information, based on the set of the observation vectors of evaluated states of feature belonging to 
marketing information (see Formula 1), is to calculate the indicator of marketing information quality. The applied Kolman's averaging quality rating method to calculate the quality indicator (Kolman 2009) is presented below.

Step 1.1 The calculation of the mean values of the evaluated states of marketing information.

Formula 2 Mean value of state of evaluated feature, $s_{c i}^{I m}$, belonging to marketing information:

$$
\overline{s_{c_{i}}^{I m}}=\frac{1}{n} \sum_{j=1}^{n} s_{c_{i}}^{I m} .
$$

Here $s_{c i}^{I m}$ is the evaluated state of $i$-marketing information feature, $i=1,2, \ldots, m$, and $m=10$, for $i=1$ (state for information amount), $i=2$ (state for information understandability), $i=3$ (state for information relevancy), $i=4$ (state for information completeness), $i=5$ (state for information being free of error), $i=6$ (state for information security), $i=7$ (state for information timeliness), $i=8$ (state for information accessibility), $i=9$ (state for information believability), $i=10$ (state for information easiness of operation), $j=1,2, \ldots, n$, and, $j$ is the number of organizational unit evaluating the states of individual features belonging to marketing information and $n \geq 4$, which results from applied qualitative and grey system theory methods and the determined minimal sample $n \geq 4$ (Cempel 2014). The mean states of evaluated marketing information features are calculated for marketing information possessed by various people of organizational units of the company communicating with the selected entities from the market environment.

Step 1.2 The calculation of the indicator of marketing information quality.

Formula 3 The indicator of marketing information quality $J^{\prime I m}$ (cf. Kolman 2009):

$$
J^{\prime I m}=\frac{1}{10} \sum_{i=1}^{10} \overline{s_{c_{i}}^{I m}} .
$$

Here $J^{\prime I m}$ is the indicator of marketing information quality, $\overline{s_{c_{i}}^{I m}}$ is the mean state of evaluated $i$-feature belonging to marketing information referring to the maximum and minimum possible respondents' scores and stated as the value between 0 and 1 . The value of the marketing information quality indicator is within $0<J^{\prime I m}<1$.

Step 1.3 The calculation of the number of the class of marketing information quality.

Formula 4 The class of evaluated state of marketing information quality (cf. Kolman 1973):

$$
K=10-\left(10 J^{\prime I m}+u\right)
$$


Table 3 Classes of the universal interpretative scale of the evaluated states of object's quality. Source: Kolman (2009)

\begin{tabular}{llll}
\hline $\begin{array}{l}\text { Class of the } \\
\text { quality }\end{array}$ & $\begin{array}{l}\text { Representative } \\
\text { value }\end{array}$ & Basic quality degrees & Name of classes of quality \\
\hline 0 & 0.95 & Set of acceptable states of quality & Excellent \\
1 & 0.85 & & Exceptional \\
2 & 0.75 & Beneficial \\
Boundary of normality $N=0.7$ & & \\
3 & 0.65 & Set of unacceptable states of quality & Convenient \\
4 & 0.55 & & Moderate \\
5 & 0.45 & & Average \\
6 & 0.35 & Inconvenient \\
7 & 0.25 & Not beneficial \\
8 & 0.15 & Critical \\
9 & 0.05 & Bad \\
\hline
\end{tabular}

Here $J^{\prime I m}$ is the value of marketing information quality indicator computed in the previous step, $u$-decimal fraction supplementing the product of $10 J^{\prime I m}$ up to the nearest integer up, $u=0$, the product $10 J^{I m}$ is an integer, and $u=1$ when $J^{I I m}=0$.

The calculated value of the marketing information quality indicator and its class are interpreted according to the adopted interpretation pattern. In the paper the universal interpretative scale of the quality states introduced by Kolman (1973) is applied. This scale is uniform (as to the value), universal (in application) and based on the set of unambiguously interpreted (with the respect of nomenclature) quality states (Kolman 2009), and was positively verified (Kijewska and Mierzwiak 2014). The set of classes of universal interpretative scale of the evaluated states of quality, with the representative values for the individual classes and the adopted nomenclature of each state is presented in Table 3. The boundary of normality is pointed on the universal interpretative scale, which indicates the so-called acceptable value of the evaluated state of the object's quality (Kolman 1973). Kolman refers to the boundary of normality with symbol $N$ and determines its value as $N=0.7$ (top boundary of the beneficial state). The determined boundary of normality divides the classes of evaluated quality states into the set of acceptable and the set of unacceptable classes of evaluated states of the object's quality.

The second step in marketing information assessment is the identification of the relations between the evaluated states of marketing information features. The grey incidence clustering model with the application of the grey incidence analysis is applied. The grey clustering enables the classification of features belonging to marketing information into classes of the similar marketing information features. It is assumed that the features belonging to the same class are aggregated and the representative feature of each class is distinguished, which leads to the simplification of the qualitative marketing information model. In the grey incidence clustering model, the system is characterized by the so-called behavioural sequences and behaviour observation vectors are 
defined (Liu and Lin 2006). In terms of marketing information quality, the behavioural sequences are represented by the states of the features belonging to marketing information, and the behaviour observation vectors are represented by observation vectors of evaluated states of individual features belonging to marketing information (see Formula 1). The relation between evaluated states of features belonging to marketing information is recognized by the computation of the closeness degree of grey incidence (Liu and Lin 2010). The closeness degree of grey incidence between the behaviour sequences $\mathrm{Yi}$ and $\mathrm{Yj}$ has been selected based on its properties appropriate for the marketing information assessment (Liu and Lin 2010; Xie and Liu 2009).

Several computations of the grey incidence clustering model and their application for marketing information quality assessment are presented below.

Step 2.1 Define the system behavioural sequences, i.e. the observation vectors of evaluated states of features belonging to marketing information, such as:

$$
\begin{aligned}
& Y_{1}=\left[y_{1}(1), y_{1}(2), \ldots, y_{1}(n)\right], \\
& Y_{2}=\left[y_{2}(1), y_{2}(2), \ldots, y_{2}(n)\right], \\
& \ldots \\
& Y_{10}=\left[y_{10}(1), y_{10}(2), \ldots, y_{10}(n)\right] .
\end{aligned}
$$

Here $Y_{1}$ is the vector of evaluated states of feature $c_{1}^{I m}, Y_{2}$-the vector of evaluated states of feature $c_{2}^{I m}, \ldots, Y_{10}$ the vector of evaluated states of feature $c_{10}^{I m}$ belonging to marketing information (see Table 2); $n$-number of organizational units evaluating the states of particular features belonging to marketing information, $n \geq 4$.

Step 2.2 Select the system operator and transform the observation vectors into the image of them. In the study of marketing information quality, the average image operator is applied (Liu and Lin 2006):

$$
\begin{aligned}
Y_{i} D_{1} & =\left(y_{i}(1) d_{1}, \quad y_{i}(2) d_{1}, \ldots, y_{i}(10) d_{1}\right), \\
y_{i}(k) d_{1} & =\frac{y_{i}(k)}{\bar{Y}_{i}}, \quad \overline{Y_{i}}=\frac{1}{n} \sum_{i=1}^{n} y_{i}(k) .
\end{aligned}
$$

Here $Y_{i} D_{1}$ stands for the image of $i$-system behaviour observation vector, and $i=1$, $2, \ldots, 10, y_{i}(k) d_{1}$ is the image of $k$-variable of $i$-system behaviour observation vector, $y_{i}(k)$ is the value of $k$-variable of $i$-system behaviour observation vector, $\bar{Y}_{i}$ is the mean value of variables of $i$-system behavior observation vector, $k$-person of organization unit, which evaluates the state of particular features belonging to marketing information, $k=1,2, \ldots, n$, and $n \geq 4$.

Step 2.3 Calculate the measures of system observation vector behaviour by summing, subtraction and quotient of their values (Liu and Lin 2010):

$$
\left|S_{i}-S_{j}\right|=\left|\sum_{k=1}^{n-1}\left[y_{i}(k) d 1-y_{j}(k) d 1\right]+\frac{1}{2}\left[y_{i}(n) d 1-y_{j}(n) d 1\right]\right| .
$$


Here $\left|S_{i}-S_{j}\right|$ is the measure of behaviour of $i$-system observation vectors and $j$-system observation vectors, $i=1,2, \ldots, 10$, and $j=1,2, \ldots, 10$.

Step. 2.4 Compute the closeness degree of grey incidence between the evaluated states of individual features belonging to marketing information (Liu and Lin 2010, s. 67):

$$
\delta_{i j}=\frac{1}{1+\left|S_{i}-S_{j}\right|} .
$$

Here $\delta_{i j}$ is the closeness degree of grey incidence between $i$-system observation vector (stated for the $i$-feature belonging to marketing information) and $j$-system observation vector (stated for the $j$-feature belonging to marketing information).

The calculated values of the closeness degree of grey incidence, $\delta_{i j}$, are set together in the system observation matrix. The values of the closeness degree of grey incidence, $\delta_{i j}$, are between 0 and 1 , the more $i$-feature and $j$-feature belonging to marketing information are similar, the greater $\delta_{i j}$, and vice versa (Liu and Lin 2010).

Step 2.5 Classify the individual features belonging to marketing information to classes with the $r$-closeness value, where $r \in[0,1]$, with the recommended value of $r>0.5$. When $\delta_{i j} \geq r$, and $i \neq j$, the evaluated states of marketing features are treated as those of the same class (Liu and Lin 2006).

As a result, features belonging to marketing information are classified. It is assumed that management activities which have the positive impact on the selected feature belonging to a given class of marketing information features also have the positive impact on the other marketing information features belonging to the same class. Thus, the recognized relations between the features belonging to marketing information simplified the model of marketing information quality. The holistic perspective for its quality management is identified, i.e. with the consideration of the states of individual features belonging to marketing information and their structure. The diagram of the designed concept of cognition and assessment of marketing information quality is presented in Fig. 1. In the developed concept, the principle of continuous improvement is applied. The continuous improvement principle is the basis for such quality management methods as, among others, PDCA Deming cycle, DMAICR cycle, DMADV cycle Six Sigma (Ranjan Senapati 2004). The cyclical nature of the designed concept is to ensure the continuous improvement of marketing information quality and research conducted for its cognition and assessment. The developed concept of cognition and assessment of marketing information quality was applied in the chosen industrial company. The purpose of its application was to verify the adopted methods and tools, as well as the perspective for their future application in marketing quality management. The obtained results are presented in the next section. 


\section{Application in the industrial company}

The developed activities of cognition and assessment of marketing information were applied in the metal industry company, the producer of cast structures from grey cast iron, ductile and stainless cast iron for the agricultural machines industry, automotive industry, ship-building industry, mining, machining, energy generation and many other industries. First, current marketing objective, such as acquisition of marketing information which facilitate the understanding of customer needs and recommendations for the product development is indicated. It is assumed that this step is implemented by the marketing management staff, with support of the industrial company's management staff and with the application of the listed basic marketing functions and objectives (see Table 1). The staff of the organizational units of the company which participate in marketing communication processes, under which the information related with the indicated objective is shaped, are selected. The selected group of staff of company organizational units, such as human resources and marketing departments, assess the actual state of marketing information quality. The online marketing information quality assessment questionnaire is prepared, based on the defined set of marketing information features and questions leading to the evaluation of their states (see Table 2). The online questionnaire was developed using the tools for creation and implementation of Google online questionnaires and sent to the management staff of the company who forwarded it to selected employees of the company's organizational units. The questionnaire was filled in independently by individual respondents. The survey was conducted in September 2018. The states of features belonging to marketing information are calculated by averaging the values of the scores given by each person to individual feature belonging to marketing information (see Formula 2). The results in the form of observation vectors of evaluated states of marketing information features are presented below:

$$
\begin{aligned}
s_{c 1}^{I m} & =[4,4,4,5,4,2.5], \quad s_{c 2}^{I m}=[3,4,5,4,3.5,4], \quad s_{c 3}^{I m}=[3.3,4.3,4.3,4.7,4,3.7], \\
s_{c 4}^{I m} & =[3,4,4,4.5,3.5,2.5], \quad s_{c 5}^{I m}=[3.5,4,5,5,4,3], \quad s_{c 6}^{I m}=[3.5,2.5,3.5,4,4,4], \\
s_{c 7}^{I m} & =[3,4,3,5,3,4], \quad s_{c 8}^{I m}=[3.7,4,4.3,5,4,3.3], \quad s_{c 9}^{I m}=[3,4,4,5,4,5], \\
s_{c 10}^{I m} & =[3,4,3.5,5,4,2]
\end{aligned}
$$

The Kolman's averaging quality rating method to calculate the quality indicator is applied (see Formula 3) and the class of evaluated state of marketing information quality is calculated (see Formula 4).

Result 1 Mean state of evaluated feature, $s_{c i}^{I m}$, belonging to the industrial company marketing information (see Formula 2):

$$
\begin{aligned}
& \overline{s_{c 1}^{I m}}=3.92, \overline{s_{c 2}^{I m}}=3.92, \overline{s_{c 3}^{I m}}=4.06, \overline{s_{c 4}^{I m}}=3.58, \overline{s_{c 5}^{I m}}=4.08, \overline{s_{c 6}^{I m}}=3.58 \text {, } \\
& \overline{s_{c 7}^{I m}}=3.67, \overline{s_{c 8}^{I m}}=4.06, \overline{s_{c 9}^{I m}}=4.17, \overline{s_{c 10}^{I m}}=3.58 \text {. }
\end{aligned}
$$


Table 4 The observation matrix of marketing information quality structure

\begin{tabular}{lllllllllll}
\hline$\delta_{i j}$ & $Y_{1}$ & $Y_{2}$ & $Y_{3}$ & $Y_{4}$ & $Y_{5}$ & $Y_{6}$ & $Y_{7}$ & $Y_{8}$ & $Y_{9}$ & $Y_{10}$ \\
\hline$Y_{1}$ & 1.000 & 0.839 & 0.883 & 0.971 & 0.954 & 0.807 & 0.815 & 0.916 & 0.781 & 0.961 \\
$Y_{2}$ & & 1.000 & 0.945 & 0.861 & 0.875 & 0.955 & 0.966 & 0.909 & 0.918 & 0.812 \\
$Y_{3}$ & & & 1.000 & 0.906 & 0.922 & 0.904 & 0.915 & 0.961 & 0.871 & 0.853 \\
$Y_{4}$ & & & & 1.000 & 0.982 & 0.827 & 0.836 & 0.942 & 0.799 & 0.935 \\
$Y_{5}$ & & & & & 1.000 & 0.840 & 0.849 & 0.958 & 0.811 & 0.919 \\
$Y_{6}$ & & & & & & 1.000 & 0.987 & 0.872 & 0.960 & 0.782 \\
$Y_{7}$ & & & & & & & 1.000 & 0.881 & 0.948 & 0.790 \\
$Y_{8}$ & & & & & & & & 1.000 & 0.841 & 0.883 \\
$Y_{9}$ & & & & & & & & & 1.000 & 0.757 \\
$Y_{10}$ & & & & & & & & & & 1.000 \\
\hline
\end{tabular}

$\delta_{i j}$ is the closeness degree of grey incidence between $i$-system observation vector $Y_{i}$ (stated for the $i$-feature belonging to marketing information) and $j$-system observation vector $Y_{j}$ (stated for the $j$-feature belonging to marketing information)

Result 2 The indicator of the industrial marketing information quality $J^{\prime \prime m}$ (see Formula 3):

$$
J^{\prime I m}=\frac{1}{10} \sum_{i=1}^{10} \overline{s_{c_{i}}^{I m}}=0.715 .
$$

Result 3 The class of evaluated state of the industrial company marketing information quality (see Formula 4):

$$
K=10-\left(10 J^{\prime I m}+u\right)=10-(7.152+0.847)=2 .
$$

The state of quality of marketing information of the industrial company is classified into second class (beneficial state of quality) of the universal interpretative scale of the quality states (see Table 3). In the presented concept of marketing information quality cognition and assessment the continuous improvement of the state of marketing information quality is assumed until its state is classified to the class of the excellent state. Thus, it is recommended to study the relations between the individual features belonging to marketing information (see the computations steps of the grey incidence clustering model presented in the fourth section of this paper). As a result, the closeness degree of grey incidence between the evaluated states of individual features belonging to marketing information is computed. The obtained results are presented in the observation matrix of marketing information quality structure.

Result 4 The observation matrix of marketing information quality structure. The calculated values of the coefficient for the closeness degree of grey incidence, $\delta_{i j}$, between $i$-system observation vector $Y i$ (stated for the $i$-feature belonging to marketing information) and $j$-system observation vector $Y j$ (stated for the $j$-feature belonging to marketing information) are summarised in Table 4. 
The classification based on the grey incidence clustering model is applied and the following classes of features belonging to marketing information, with the $r$-similarity level $(r=0.96)$ are distinguished.

Result 5 The classes $K_{i}$ of features belonging to marketing information:

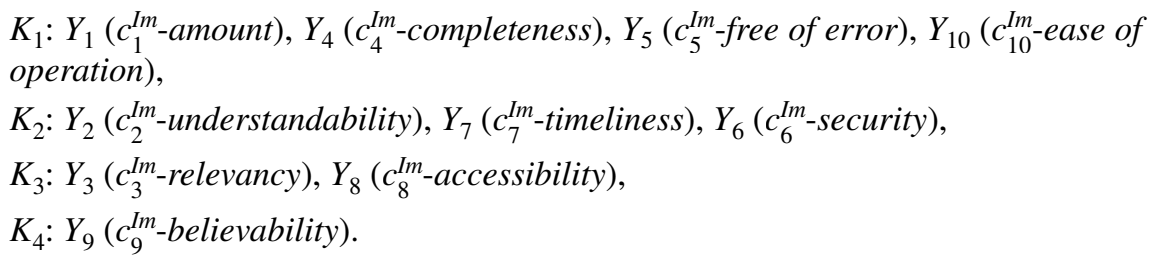

Based on the recognized relations between the marketing information features, four classes of similar features are identified. The classification of features belonging to marketing information leads to a simplified model of marketing information quality. It is assumed that features belonging to the given class have similar properties. This means that the company's management should undertake activities to improve the states of selected features belonging to marketing information which representing the given classes, also have the positive impact on the qualitative changes in marketing information quality in a holistic perspective.

The effectiveness of the developed concept of cognition and assessment of the quality of marketing information has been checked in the scope of assessing the effectiveness of examining the states of individual characteristics of marketing information, the effectiveness of Kolman's averaging quality rating method to calculate the quality indicator, as well as the effectiveness of grey cluster method to study of the relations between the states of individual marketing information features. The assessment assumed the existence of three types of activities (Kotarbiński 1975), i.e. effective measures (bringing closer to the objective of the activity), ineffective measures (leading to the objective of the activity but in an insufficient manner) and anti-effective measures (not leading to the objective of the activity). As a result of the application of the method in the selected industrial company, the effectiveness of testing the quality of information, the calculation of the quality index and the determination of the quality class of marketing information and the classification of its characteristics have been confirmed.

\section{Conclusion and outlook}

The presented concept of cognition and assessment of marketing information quality integrates the basic qualitative principles and operations with the grey incident analysis. The concept introduced enables the recognition of the quality of marketing information in a holistic approach. The marketing information quality and the evaluated marketing information quality was defined. Based on the literature analysis, the set of features belonging to marketing information and its 
evaluation criteria related with marketing functions and objectives was formed. The qualitative averaging quality rating method to calculate the quality indicator and the universal interpretative scale of the quality states were applied. The classes of the marketing information quality are indicated. The structure of marketing information quality is studied with the application of grey incidence clustering model. The presented concept of cognition and assessment of marketing information was applied in the chosen industrial company. As a result, the developed concept has been proved in terms of the correctness of the applied calculation formulas. The possibility to identify the structure of marketing information quality and indicate the recommended activities leading to marketing information quality improvement in a holistic perspective have been confirmed. The effectiveness of the developed method has been assessed by checking whether certain actions are effective, i.e. whether they bring us closer to achieving the set goals. The objective of further research is to assess the economics of the method, economics understood in the praxeological sense (Kotarbiński 1975). This manifest itself in the pursuit of using only as much resources as it is necessary for the implementation of individual objectives leading to the cognition and assessment of the quality of marketing information. This assessment will be implemented in two areas, i.e. efficiency evaluation and evaluation of the savings of activities leading to the cognition and assessment of the quality of marketing information. At the same time, it is assumed that someone who "with the same consumption of a given type of resources and a given type of purchase achieves a greater proportion of acquisitions" works more efficiently, and someone who "with respect to a given type of resources and a given type of purchase, obtains the same the measure of such acquisitions at the price of a smaller consumption of this type of resources " works more economically (Kotarbiński 1975). Another direction of further research is to conduct the comparative analysis with other methods of information quality assessment and development of a verified method for marketing information quality cognition and assessment for industrial companies. It is also possible to apply the Clusters with the Variable Weights method and a mathematical model using optimization functions in order to separate the appropriate features of marketing information as features representing individual clusters, in such a way that leads to the extraction of the features with the highest value in relation to the current and important marketing objectives of an industrial enterprise. The objective of further research is to consider also the mathematical optimization models using for multi-choice (referring to the sources of marketing information), multi-objective (referring to the various marketing functions) problem, incorporating the goal preferences of the marketing decision maker (Mahapatra et al. 2013; Roy et al. 2017a, b, c) and to consider the heuristic approaches to improve the management of marketing information quality (Das et al. 2019). In addition, an important objective of further research is to identify the possibilities of integration of the prepared concept within the structure of marketing activities in industrial companies. 
Acknowledgements The relevant research described in this paper is carried out within the research project of Poznan University of Technology at the Faculty of Engineering Management and financed with the funds for the development of young scientists (No. 11/142/DSMK/0995).

Open Access This article is distributed under the terms of the Creative Commons Attribution 4.0 International License (http://creativecommons.org/licenses/by/4.0/), which permits unrestricted use, distribution, and reproduction in any medium, provided you give appropriate credit to the original author(s) and the source, provide a link to the Creative Commons license, and indicate if changes were made.

\section{References}

Andersen PH (2001) Relationship development and marketing communication: an integrative model. J Bus Ind Market 16(3):167-183

Aristotle (2012) The metaphysics. Translated by Ross WD, Edited by Roger Bishop Jones

Azgaldov GG, Kostin AV, Omiste AEP (2015) The ABC of Qualimetry. M.: Ridero

Bizer C, Cyganiak R (2009) Quality-driven information filtering using the WIQA policy framework. J Web Semant 7(1):1-10

Borden NH (1964) The concept of the marketing mix. J Advert Res 4(2):2-7

Borys T (1980) Elementy teorii jakości. Państwowe Wydawnictwo Naukowe, Warszawa

Borys T (2012) Interdyscyplinarność nauk o jakości. Zarządzanie i Finanse 10(3):7-23

Bovee M, Srivastava RP, Mak B (2003) A conceptual framework and belief-function approach to assessing overall information quality. Int J Intell Syst 18(1):51-74

Bruhn M, Georgi D (2006) Services marketing managing the service value chain. Financial Times Prentice Hall, New York

Cempel C (2014) Teoria szarych systemów-nowa metodologia analizy i oceny złożonych systemów. Przegląd możliwości, Zeszyty Naukowe Politechniki Poznańskiej. Organizacja i Zarządzanie 63:9-20

Chen CC, Tseng YD (2011) Quality evaluation of product reviews using an information quality framework. Decis Support Syst 50(4):755-768

Crosby PB (1985) Quality without tears. New American Library, New York

Das SK, Roy SK, Weber GW (2019) Heuristic approaches for solid transportation-p-facility location problem. Cent Eur J Oper Res. https://doi.org/10.1007/s10100-01900610-7

Deming WE (1986) Out of the crisis. Cambridge, MA: Massachusetts Institute of Technology Center for Advanced Engineering Study

Feigenbaum A (1951) Quality control—principles, practice and administration. MCGraw-Hill, New York

Goi CL (2009) A review of marketing mix: 4Ps or more? Int J Market Stud 1(1):2

Graczyk-Kucharska M, Szafrański M, Goliński M, Spychała M, Borsekova K (2018) Model of competency management in the network of production enterprises in industry 4.0-assumptions. In: Advances in manufacturing. Springer, Cham, pp 195-204

Grönroos Ch (1994) From marketing mix to relationship marketing. Manag Decis 32(2):4-20

Grönroos C (1995) Relationship marketing: the strategy continuum. J Acad Mark Sci 23(4):252-254

Hermann M, Pentek T, Otto B (2016) Design Principles for Industrie 4.0 scenarios. In: Proceeding HICSS' 16 Proceedings of the 49th Hawaii international conference on system sciences, pp 3928-3937

Holm O (2006) Integrated marketing communication: from tactics to strategy. Corp Commun Int $\mathrm{J}$ 11(1):23-33

ISO 9001:2015, International Standard ISO 9001, Fifth edition

Jiao L, Pan Q, Liang Y, Feng X, Yang F (2016) Combining sources of evidence with reliability and importance for decision making. CEJOR 24(1):87-106

Juran JM (1992) Juran on quality by design. The new steps for planning quality into goods and services. The Free Press, Mumbai

Kaya O, Caner S (2018) Supply chain contracts for capacity decisions under symmetric and asymmetric information. CEJOR 26(1):67-92 
Keller KL (2001) Mastering the marketing communications mix: micro and macro perspectives on integrated marketing communication programs. J Market Manag 17(7-8):819-847

Keller KL (2010) Brand equity management in a multichannel, multimedia retail environment. J Interact Market 24:8-70

Kijewska J, Goliński M (2017) Conceptual framework for marketing communication management with a qualitative and system-oriented approach. J Eur TRIZ Assoc Innov 1(03):14-18

Kijewska J, Mierzwiak R (2014) Empiryczna weryfikacja uniwersalnej skali stanów względnych. Przedsiębiorczość i Zarządzanie, Wydawnictwo SAN XV (10, I) Łódź-Garwolin

Kitchen PJ, Burgmann I (2015) Integrated marketing communication: making it work at a strategic level. J Bus Strategy 36(4):34-39

Knight SA, Burn J (2005) Developing a framework for assessing information quality on the World Wide Web. Inf Sci 8:160-162

Kolman R (1973) Ilościowe określanie jakości. Państwowe Wydawnictwo Ekonomiczne

Kolman R (2009) Kwalitologia: wiedza o różnych dziedzinach jakości. Wydawnictwo Placet, Warszawa

Kolman R, Grudowski P, Pytko B (2009) Cross-cultural problem of quality. In: Sułkowski Ł, Waniek K (eds) Studia z zarządzania międzykulturowego cz II. Społeczna Wyższa Szkoła Przedsiębiorczości i Zarządzania, Łódź, pp 275-283

Korhonen-Sande S, Sande JB (2014) Getting the most out of cross-functional cooperation: internal structural change as a trigger for customer information use. Ind Mark Manag 43(8):1394-1406

Kosacka M, Mierzwiak R, Golinska-Dawson P (2015) Sustainability classification for SMEs—a guidance of sustainability assessment with the use of averaged traits quality method. Toward Sustainable Operations of Supply Chain and Logistics Systems. Springer, Cham, pp 141-152

Kotarbiński T (1975) Hasło Dobrej roboty. Państwowe Wydawnictwo Wiedza Powszechna, Warszawa

Kotler P, Keller KL (2012) Marketing management, 14th edn. Pearson Education Limited, Bengaluru

Kropat E, Weber GW, Pedamallu CS (2009) Regulatory networks under ellipsoidal uncertainty-optimization theory and dynamical systems. Preprint 138

Langefors B (1980) Infological models and information users view. Inf Syst 5:17-32

Lee YW, Strong DM, Kahn BK, Wang RY (2002) AIMQ: a methodology for information quality assessment. Inf Manag 40:133-146

Li J, Yang M, Zhao X (2018) Quantifying and mitigating inefficiency in information acquisition under competition. Cent Eur J Oper Res. https://doi.org/10.1007/s10100-018-0529-8

Liang Z, Shi D Li, Wierman MJ (2006) Information entropy, rough entropy and knowledge granulation in incomplete information systems. Int J Gen Syst 35(6):641-654

Lindgreen A, Crawford I (1999) Implementing, monitoring and measuring a programme of relationship marketing. Market Intell Plan 17(5):231-239

Liu S, Lin Y (2006) Grey information: theory and practical applications. Springer, New York

Liu S, Lin Y (2010) Grey systems: theory and applications. Springer, Berlin

Liu S, Yang Y, Forrest J (2017) Grey data analysis. Springer, Berlin

Loots H, Grobler AF (2014) Review Applying marketing management and communication management theories to increase client retention in the short-term insurance industry. Public Relat Rev 40:328-337

Lu SY, ElMaraghy W, Schuh G, Wilhelm R (2007) A scientific foundation of collaborative engineering. CIRP Ann Manuf Technol 56(2):605-634

Mahapatra DR, Roy SK, Biswal MP (2013) Multi-choice stochastic transportation problem involving extreme value distribution. Appl Math Model 37(4):2230-2240

Maity G, Roy SK, Verdegay JL (2016) Multi-objective transportation problem with cost reliability under uncertain environment. Int J Comput Intell Syst 9(5):839-849

Maity G, Mardanya D, Roy SK, Weber GW (2019) A new approach for solving dual-hesitant fuzzy transportation problem with restrictions. Sādhanā 44:75. https://doi.org/10.1007/s12046-018-1045-1

Majchrzak J (2018) The integrated marketing communication quality management method of an industrial company. Ph.D. thesis, Poznan University of Technology, Faculty of Engineering Management

Małecka J (2018) The perception of quality in qualitology: selected aspects. In: ECRM 2018 17th European conference on research methods in business and management, pp 246-253

Mantura W (2010) Zarys kwalitologii. Wydawnictwo Politechniki Poznańskiej, Poznań

Mantura W (2012) Comperative analysis of the category of quality information. In: Goliński M, Szafrański M (eds) Integrated support system for access to information in urban space with use of GPS and GIS systems. Publishing House of Poznan, University of Technology, Poznan, pp 7-30 
Mantura W (2015) Rozważania o współczesnych problemach marketingu. Zeszyty Naukowe Uniwersytetu Szczecińskiego. Studia i Prace Wydziału Nauk Ekonomicznych i Zarządzania 39 (2) Wydawnictwo Naukowe Uniwersytetu Szczecińskiego:11-23

Maurer H, Mehmood R (2015) Merging image databases as an example for information integration. CEJOR 23(2):441-458

McCarthy EJ (1964) Basic marketing. Richard D. Irwin, IL

Michnik J, Lo MC (2009) The assessment of the information quality with the aid of multiple criteria analysis. Eur J Oper Res 195(3):850-856

Mirbagheri SA, Hejazinia M (2010) Mobile marketing communication: learning from 45 popular cases for campaign designing. Int J Mob Market 5(1):175-192

Mruk H, Pilarczyk B, Sojkin B, Szulce H (1996) Podstawy marketingu. Wydawnictwo Akademii Ekonomicznej, Poznań

Parasuraman A, Zeithaml VA, Berry LL (1988) Servqual: a multiple-item scale for measuring consumer perceptions of service quality. J Retail 64(1):12

Raghunathan S (1999) Impact of information quality and decision-maker quality on decision quality: a theoretical model and simulation analysis. Decis Support Syst 26:275-286

Rajnoha R, Kádárová J, Sujová A, Kádár G (2014) Business information systems: research study and methodological proposals for ERP implementation process improvement. Proc Soc Behav Sci 109:165-170

Ranjan Senapati N (2004) Six Sigma: myths and realities. Int J Qual Reliab Manag 21(6):683-690

Roy SK, Maity G, Weber GW (2017a) Multi-objective two-stage grey transportation problem using utility function with goals. CEJOR 25(2):417-439

Roy P, Kumar R, Sharma S (2017b) A novel fuzzy document based information retrieval model for forecasting. Fuzzy Inf Eng 9(2):137-159

Roy SK, Maity G, Weber GW, Gök SZA (2017c) Conic scalarization approach to solve multi-choice multiobjective transportation problem with interval goal. Ann Oper Res 253(1):599-620

Roy SK, Midya S, Yu VF (2018) Multi-objective fixed-charge transportation problem with random rough variables. Int J Uncertain Fuzziness Knowl Based Syst 26(06):971-996

Salvendy G (2012) Handbook of human factors and ergonomics, 4th edn. Wiley, Hoboken

Schultz DE, Schultz HF (1998) Transitioning marketing communication into the twenty-first century. J Market Commun 4(1):9-26

Shankaranarayanan G, Yu Cai (2006) Supporting data quality management in decision-making. Decis Support Syst 42:302-317

Sienkiewicz P (1983) Inżynieria Systemów. Wydawnictwo Ministerstwa Obrony Narodowej, Warszawa

Słowiński R, Stefanowski J, Greco S, Matarazzo B (2000) Rough set based processing of inconsistent information in decision analysis. Control Cybern 29(1):379-404

Sower VE, Fair FK (2005) Twhere is more to quality than continuous improvement: listening to Plato. Qual Manag J 12(1):8-20

Spychała M, Szafrański M, Graczyk-Kucharska M, Goliński M (2017) The method of designing reference models of workstations. In: Marimon F, Mas-Machuca M, Berbegal-Mirabent J, Bastida R (eds) Proceedings of the 18th European conference on knowledge management ECKM 2017. Academic Conferences and Publishing International Limited, Barcelona, pp 930-939

Sundgren B (1973) An infological approach to data bases. Stockholm, Skriftserie

Szafrański M (2017) Models of businesses' support for technical knowledge development in Wielkopolska Region-a qualitology approach. In: 6th Central European conference in regional science-CERS:128-137

Szafrański M, Goliński M, Graczyk-Kucharska M, Spychała M (2019) Cooperation of education and enterprises in improving professional competences-analysis of needs. Advances in manufacturing II. Springer, Cham, pp 155-168

Wand Y, Wang RY (1996) Anchoring data quality dimensions in ontological foundations. Commun ACM 39(11):86-95

Wang RY (1998) A product perspective on total data quality management. Commun ACM 41(2):58-65

Weber GW, Kropat E, Alparslan Gök SZ (2008) Semi-infinite and conic optimization in modern human life and financial sciences under uncertainty. In: ISI Proceedings of 20th Mini-EURO conference, Continuous Optimization and Knowledge-Based Technologies, Neringa, Lithuania, pp 180-185

Więcek-Janka E, Wyrwicka MK, Jaźwińska D, Contreras Loera M (2017) Application of the postulates of sustainable development in family businesses in the light of empirical research. In: Nalepka A, UjwaryGil A (eds) Proceedings of the 16th International Conference, Business and non-profit organizations 
facing increased competition and growing customer's demands, vol 16, Tomaszowice, Poland, pp $441-455$

Wirtz J, Tuzovic S, Kuppelwieser VG (2014) The role of marketing in today's enterprises. J Serv Manag 25(2):171-194

Xie N (2013) On computational algorithms of grey numbers based on information background. Grey Syst Theory Appl 3(2):177-190

Xie N, Liu S (2009) Research on evaluations of several grey relational models adapt to grey relational axioms. J Syst Eng Electron 20(2):304-309

Publisher's Note Springer Nature remains neutral with regard to jurisdictional claims in published maps and institutional affiliations. 